\title{
Aging with a Neurodisability: Morbidity and Life Expectancy Issues
}

\author{
Michael J. DeVivo* \\ Department of Physical Medicine and Rehabilitation, University of Alabama at Birmingham, Birmingham, AL, USA
}

This issue of NeuroRehabilitation focuses on life expectancy and aging-related morbidity for persons with a neurologic disability. Papers were contributed on four neurologic disabilities: spinal cord injury; traumatic brain injury; multiple sclerosis; and cerebral palsy. Each of these papers provides valuable new information and insights into the aging process and also demonstrates the inherent difficulties of studying the effects of aging among persons with and without neurologic disabilities. These difficulties include separating the effects of current age, time post-onset (duration of disability), age at onset, and calendar time (treatment era effects) as well as controlling for survivor effects as time post-onset increases. While cross-sectional studies can provide important clues to the effects of aging, have the advantage of relatively low cost, and can be done efficiently and over a relatively short period of time, they can also produce misleading results when interpreted in the context of aging. Therefore, appropriately designed cohort (longitudinal) studies that track changes within people over time as they age must eventually be conducted to confirm the aging-related conclusions obtained from cross-sectional studies.

Extensive literature already exists on long-term survival and life expectancy after spinal cord injury [2$8,10,14]$. Life expectancy following multiple sclerosis is typically reduced by only a few years if at all. How-

*Address for correspondence: Michael J. DeVivo, Dr.P.H., 515 Spain Rehabilitation Center, 1717 Sixth Avenue South, Birmingham, AL 35233-7330, USA. Tel.: +1 205934 3320; Fax: +1 205934 2709; E-mail: devivo@uab.edu. ever, life expectancy following cerebral palsy [11,12] and traumatic brain injury $[1,9,13]$ is less well documented. Two new complementary studies of long-term survival following traumatic brain injury appear in this issue. Brown et al. conducted a population-based study and found a relatively high mortality rate during the first six months after traumatic brain injury, particularly for moderately to severely impaired persons. However, after the first six months, survival rates were not much reduced from normal. Conversely, Harrison-Felix et al. found a long-term mortality rate that was twice as high as that of the general population of comparable age, sex, race, and length of follow-up. The difference undoubtedly lies in the nature of the two study populations, the Harrison-Felix study involving a much more severely impaired group of patients on average than the short-term survivors included in the Brown study. Overall, these studies demonstrate that life expectancy is quite high for persons with traumatic brain injury who survive the first few months post-injury, but is clearly reduced for the most severely impaired persons.

Strauss et al. provide new data on the long-term survival prospects of persons with cerebral palsy that extends their previous work. Long-term survival is found to be quite high for those with good mobility; a finding that is similar to the high life expectancies found among persons with mild to moderate traumatic brain injury or incomplete motor-functional spinal cord injury. However, those with more severe impairment have life expectancies that are considerably reduced from normal. 
Most literature on cerebral palsy focuses on children, and rightly so. However, research on older persons with cerebral palsy is also needed. In their paper, Strauss et al. find that many persons with cerebral palsy continue to function well in their 60's and 70's, but declines in function often occur, and can be demonstrated more dramatically from cohort analyses than cross-sectional analyses.

Hammond et al. find that most persons with traumatic brain injury do not experience changes in function during the first five years post-injury. In fact, some persons actually demonstrate functional improvement during this time, and only a few deteriorate. With continued funding of the traumatic brain injury model system program, longer-term follow-up studies to assess issues of aging, similar to those that have been done with the spinal cord injury model system database, will eventually be possible.

In addition to model systems, the National Institute on Disability and Rehabilitation Research has funded two medical rehabilitation research and training centers on aging with a spinal cord injury. One paper from each of those centers is included in this issue. In the first paper, Adkins provides a thorough discussion of the complexities and practical limitations of conducting studies of the effects of aging in the spinal cord injury population. Most of the issues he raises also apply both to studies of aging in persons with other disabilities and general population aging studies. He also provides a review of systems and medical issues related to aging with a spinal cord injury.

Charlifue et al. complement the review of Adkins by examining quality of life and psychosocial outcomes over time as persons age with spinal cord injury. They find that persons with spinal cord injury report consistently high quality of life, and that current quality of life is predictive of future levels of depression, stress and general well-being. Once again, cohort analyses are demonstrated to be more revealing than cross-sectional analyses.

Finally, Minden et al. present the first results from the Sonya Slifka Longitudinal Multiple Sclerosis Database. They find that persons over age 65 tend to have moderate to severe disability and greater disability than younger persons. They find that many older persons with multiple sclerosis may have unmet needs secondary to inadequate health insurance and prescription drug coverage. Interestingly, they also find that disease course and length of time post-diagnosis are stronger predictors of current status than current age and other demographic factors. Subsequent studies with the lon- gitudinal component of this database will be needed to confirm and expand upon these findings.

Taken together, these papers provide an interesting look at the effects of aging with a neurologic disability. Given the long life expectancies that persons with neurologic disabilities now enjoy, these papers also suggest possible directions and priorities for future research on this increasingly important topic.

\section{References}

[1] I. Baguley, S. Slewa-Younan, R. Lazarus and A. Green, Longterm mortality trends in patients with traumatic brain injury, Brain Injury 14 (2000), 505-512.

[2] M.J. DeVivo and C.S. Ivie, Life expectancy of ventilatordependent persons with spinal cord injuries, Chest 108 (1995), 226-232.

[3] M.J. DeVivo, J.S. Krause and D.P. Lammertse, Recent trends in mortality and causes of death among persons with spinal cord injury, Archives of Physical Medicine and Rehabilitation 80 (1999), 1411-1419.

[4] M.J. DeVivo and S.L. Stover, Long-term survival and causes of death, in: Spinal cord injury: clinical outcomes from the model systems, S.L. Stover, J.A. DeLisa and G.G. Whiteneck, eds, Aspen Publishers, Maryland, 1995, pp. 289-316.

[5] H.L. Frankel, J.R. Coll, S.W. Charlifue, G.G. Whiteneck, B.P. Gardner and M.A. Jamous et al., Long-term survival in spinal cord injury: a fifty year investigation, Spinal Cord 36 (1998), 266-274.

[6] A. Hartkopp, H. Bronnum-Hansen and A.M. Seidenschnur et al., Survival and cause of death after traumatic spinal cord injury: a long-term epidemiological survey from Denmark, Spinal Cord 35 (1997), 76-85.

[7] J.S. Krause, M. Sternberg, J. Maides and S. Lottes, Mortality after spinal cord injury: an 11-year prospective study, Archives of Physical Medicine and Rehabilitation 78 (1997), 815-821.

[8] G.P. Samsa, C.H. Patrick and J.R. Feussner, Long-term survival of veterans with traumatic spinal cord injury, Archives of Neurology 50 (1993), 909-914.

[9] R.M. Shavelle and D.J. Strauss, Comparative mortality of adults with traumatic brain injury in California, 1988-1997, Journal of Insurance Medicine 32 (2000), 163-166.

[10] D.J. Strauss, M.J. DeVivo and R.M. Shavelle, Long-term mortality risk after spinal cord injury, Journal of Insurance Medicine 32 (2000), 11-16.

[11] D.J. Strauss and R.M. Shavelle, Life expectancy of adults with cerebral palsy, Developmental Medicine \& Child Neurology 40 (1998), 369-375.

[12] D.J. Strauss, R.M. Shavelle and T.W. Anderson, Life expectancy of children with cerebral palsy, Pediatric Neurology 18 (1998), 143-149.

[13] D.J. Strauss, R.M. Shavelle and T.W. Anderson, Long term survival of children and adolescents after traumatic brain injury, Archives of Physical Medicine and Rehabilitation 79 (1998), 1095-1100.

[14] J.D. Yeo, J. Walsh, S. Rutkowski, R. Soden, M. Craven and J. Middleton, Mortality following spinal cord injury, Spinal Cord 36 (1998), 329-336. 